Discussion Paper No. 05-06

The Efficiency Costs of Separating Carbon Markets Under the EU Emissions Trading Scheme:

A Quantitative Assessment for Germany

Christoph Böhringer, Tim Hoffmann and

Casiano Manrique de Lara Peñate

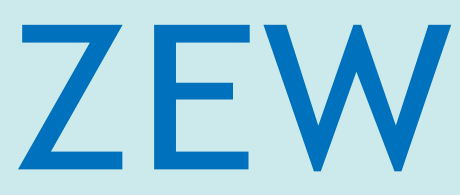

Zentrum für Europäische Wirtschaftsforschung $\mathrm{GmbH}$

Centre for European

Economic Research 
Discussion Paper No. 05-06

\title{
The Efficiency Costs of Separating Carbon Markets Under the EU Emissions Trading Scheme: A Quantitative Assessment for Germany
}

\author{
Christoph Böhringer, Tim Hoffmann and \\ Casiano Manrique de Lara Peñate
}

Download this ZEW Discussion Paper from our ftp server:

ftp://ftp.zew.de/pub/zew-docs/dp/dp0506.pdf

Die Discussion Papers dienen einer möglichst schnellen Verbreitung von neueren Forschungsarbeiten des ZEW. Die Beiträge liegen in alleiniger Verantwortung der Autoren und stellen nicht notwendigerweise die Meinung des ZEW dar.

Discussion Papers are intended to make results of ZEW research promptly available to other economists in order to encourage discussion and suggestions for revisions. The authors are solely responsible for the contents which do not necessarily represent the opinion of the ZEW. 


\section{Nontechnical Summary}

From 1 January 2005 onwards the European Union has launched the first large-scale international emissions trading program. The EU Emissions Trading Scheme (EU-ETS) in principle has the opportunity to advance the role of market-based policies in environmental regulation and to form the basis for future European and international climate policies.

The EU-ETS under the European Burden Sharing Agreement implies a hybrid regulation scheme as sectors of domestic economies that are not covered by the emissions trading scheme require complementary emission regulation. Under such a hybrid scheme, the domestic regulator must have perfect information on the international price of tradable emission allowances as well as the emission abatement possibilities across all domestic emission sources in order to implement a cost-minimizing abatement policy.

In this paper, we demonstrate that a lack of central planner information may seriously limit the efficiency of hybrid regulation. The deficiency of hybrid regulation becomes particularly policy-relevant when the distributional constraints for the design of the EU-ETS are taken into account. In fact, the EU-ETS has been only approved by EU Member States under the condition that emission allowances to sectors covered by the trading scheme are handed out for free. Whereas lump-sum grandfathering of allowances would not interfere with overall efficiency in a single comprehensive emission market, this is no longer the case with hybrid markets. Numerical simulations based on empirical data for Germany illustrate impending large efficiency losses if allowance allocation to EU-ETS sectors exceeds the efficient level. 


\title{
The Efficiency Costs of Separating Carbon Markets under the EU Emissions Trading Scheme: A Quantitative Assessment for Germany
}

\author{
Christoph Böhringer ${ }^{\mathrm{a}, \mathrm{b}}$, Tim Hoffmann ${ }^{\mathrm{a}}$, Casiano Manrique de Lara Peñate ${ }^{\mathrm{c}}$
}

\begin{abstract}
From 1 January 2005 onwards the European Union has launched the first largescale international carbon emissions trading program. As the EU Emissions Trading Scheme (EU-ETS) covers only part of domestic carbon emissions, it implies a hybrid environmental regulation scheme: Each EU Member State must specify additional domestic abatement policies for the sectors that are not covered by the emissions trading scheme in order to meet its emissions budget under the EU Burden Sharing Agreement. Based on numerical simulations for Germany, we illustrate the efficiency drawback of hybrid carbon regulation which becomes particularly relevant when distributional constraints of the current EU-ETS design are taken into account.
\end{abstract}

JEL classification: D61, H21, Q48

Keywords: emissions trading, hybrid regulation, National Allocation Plans

\footnotetext{
${ }^{\text {a }}$ Centre for European Economic Research (ZEW), P.O. Box 10 34 43, 68034 Mannheim, Germany.

${ }^{\mathrm{b}}$ Department of Economics, University of Heidelberg, Germany.

${ }^{c}$ Department of Applied Economics, University of Las Palmas, Spain.
}

Corresponding author: boehringer@zew.de 


\section{Introduction}

Since long, economists have advocated the efficiency advantages of market-based instruments, i.e., emission taxes or tradable emission allowances over command-and-control standards. The basic reasoning behind this is that taxes or tradable allowances can achieve the same marginal costs for each use of a given pollutant so that the economy as a whole will employ the cheapest abatement options. While a deliberate design of standards could in principle also achieve costeffective abatement, the fundamental advantage of market-based regulation is that costefficiency can be obtained by decentralized market mechanisms: There are no information requirements for the regulator on the specific abatement options across different pollution sources to assure equalization of marginal abatement costs.

During the last decade, in particular emission taxes have played a growing role in domestic environmental policies of OECD countries - not at least because efficiency arguments promoted overall political feasibility (OECD 2001). The most recent prominent example for the market-based course in environmental policy design is the European Union's Emissions Trading Scheme (EU-ETS) being in force since the first of January 2005 (EU 2003a). Its key objective is to foster cost-efficiency of carbon reduction under the EU Burden Sharing Agreement (EU-BSA) that entails specific emission reduction targets across EU Member States (EU 1999) in line with the EU's overall reduction commitment under the Kyoto Protocol. ${ }^{1}$

Initially, the EU-ETS will only cover carbon dioxide $\left(\mathrm{CO}_{2}\right)$ emissions from selected energyintensive sectors including: production and processing of iron and steel; production of cement, glass, or ceramic; energy transformation (electricity generation and oil refineries). According to Article 10 of the EU-ETS-Directive, emission allowances to these sectors will be grandfathered, i.e. given for free. ${ }^{2}$ Each Member State is obligated to set up a National

\footnotetext{
${ }^{1}$ Under the Kyoto Protocol the EU is committed to cut its annual greenhouse gas emissions during 2008-2012 by $8 \%$ on average as compared to 1990 emission levels (UNFCCC 1997).

${ }^{2}$ More specifically, Member States must allocate at least $95 \%$ of emission allowances for free in the "warm-up" phase from 2005 to 2007. In the next phase - from 2008 to 2012 - this threshold can be reduced to $90 \%$, whereas the ceilings for later phases have been not yet decided upon.
} 
Allocation Plan (NAP) where it defines the cap on emission allowances for sectors (installations) included in the trading scheme and the specific allocation rule for grandfathering. The NAPs had to be submitted to the EU Commission by April 2004 for official review and approval.

As the EU-ETS covers only a part of $\mathrm{CO}_{2}$ emission sources, it implies a hybrid environmental regulation scheme. Each Member State must complement the EU-ETS with specific domestic abatement policies for the sectors that are not covered by the emissions trading scheme in order to meet the country's total emissions budget under the EU-BSA. The segmentation of the emission market into multiple domestic markets and a single international market creates a fundamental information problem for environmental regulation that seems to be widely ignored in the public policy debate: Under a hybrid scheme, the domestic regulator must have perfect information on the international price of tradable emission allowances and the marginal abatement cost curves across all domestic emission sources in order to implement the (single) cost-minimizing NAP. Hence, hybrid emission regulation as implied by the EU-ETS discards a key element of market-based regulation, i.e. the rigorous use of decentralized market mechanisms.

In this paper, we investigate the potential efficiency costs of hybrid carbon emission regulation. We start with a simple analytical partial equilibrium framework to demonstrate the fundamental problem of hybrid regulation. We then quantify the excess costs of hybrid regulation for Germany using marginal carbon abatement cost curves based on empirical data.

Our analysis complements recent research on the economic impacts of the EU-ETS that emphasized the distortionary effects of dynamic (updating) allocation rules (see e.g. Böhringer and Lange 2005a) or competitive distortions between similar energy-intensive firms across EU Member States (see e.g. Böhringer and Lange 2005b). This paper highlights the fundamental information problems and induced efficiency costs of hybrid carbon regulation from the perspective of national authorities. 


\section{Stylized Analysis}

Under the EU-BSA, a Member State must comply with a country-specific emissions budget $\bar{E}$. With international emissions trading, efficient national regulation comes down to minimizing compliance costs as the sum of abatement costs $C_{i}\left(e_{i}\right)$ across all domestic sectors $i$ and the costs of buying emission allowances from the international market at an exogenous price $\bar{p}:^{3}$

$$
\operatorname{Min}_{e_{i}} \sum_{i} C_{i}\left(e_{i}\right)+\bar{p}\left(\sum_{i} e_{i}-\bar{E}\right)
$$

The associated first-order condition states that marginal abatement costs are equalized across all sectors at the international emissions price:

$$
\bar{p}=-\frac{\partial C_{i}}{\partial e_{i}}
$$

From the perspective of the national regulator, the efficient solution can be decentralized by implementing an open emissions trading scheme where the national emissions budget $\bar{E}$ is auctioned or grandfathered. In this way, the national authority does neither require any information on domestic abatement technologies (i.e., the marginal costs of domestic abatement options) nor on the international emissions price: The cost-efficient abatement across sectors together with exports or imports of emission allowances are implicitly determined by decentralized market mechanisms. For hybrid emission regulation under the EU-ETS, however, the national regulator must know both - the international carbon value $\bar{p}$ as well as (marginal) abatement cost curves for all domestic emission sources - in order to partition the national emissions budget $\bar{E}$ into cost-efficient segments $E_{D I R}^{*}$ for the EU-ETS sectors (thereafter referred to as DIR sectors that are covered by the ETS-Directive) and $E_{N D I R}^{*}=\bar{E}-E_{D I R}^{*}$ for the remaining sectors of the domestic economy (thereafter referred to as NDIR sectors that are not covered by the ETS-Directive). Furthermore, the hybrid approach

\footnotetext{
${ }^{3}$ As usual, $\partial C_{i} / \partial e_{i} \leq 0$ and $\partial^{2} C_{i} / \partial e_{i}{ }^{2}>0$ where $e_{i}$ denote emissions by sector $i$. Countries are assumed to be price takers on the international emission market.
} 
destroys the flexibility for grandfathering policies even if perfect information would be available: The efficient level of $E_{D I R}^{*}$ constitutes the upper bound at which emission allowances to EU-ETS sectors could be given for free (lump-sum) without reducing overall efficiency.

Figure 1 illustrates the impending excess costs of hybrid market regulation. The aggregate marginal abatement cost curve for DIR sectors is denoted by $-\partial C_{D I R} / \partial e_{i}$ and for $N D I R$ sectors by $-\partial C_{N D I R} / \partial e_{i}$ respectively; the two marginal cost curves add up to the overall marginal abatement cost curve $-\partial C / \partial e_{i}$. The intersection of the international emissions price $\bar{p}$ with the marginal abatement cost curves determines the optimal partitioning of the overall emissions budget $\bar{E}$ : NDIR sectors should comply with an emissions constraint $E_{\text {NDIR }}^{*}$ whereas the remaining emissions budget $E_{D I R}^{*}=\bar{E}-E_{N D I R}^{*}$ should be allocated to the DIR sectors. If domestic marginal abatement costs to reach the overall emission target $\bar{E}$ are below the international emissions price, the region becomes an exporter of emission allowances (as sketched in Figure 1) with optimal domestic emissions $E^{*}$ below the mandated emissions budget $\bar{E}$; otherwise, the region becomes an importer.

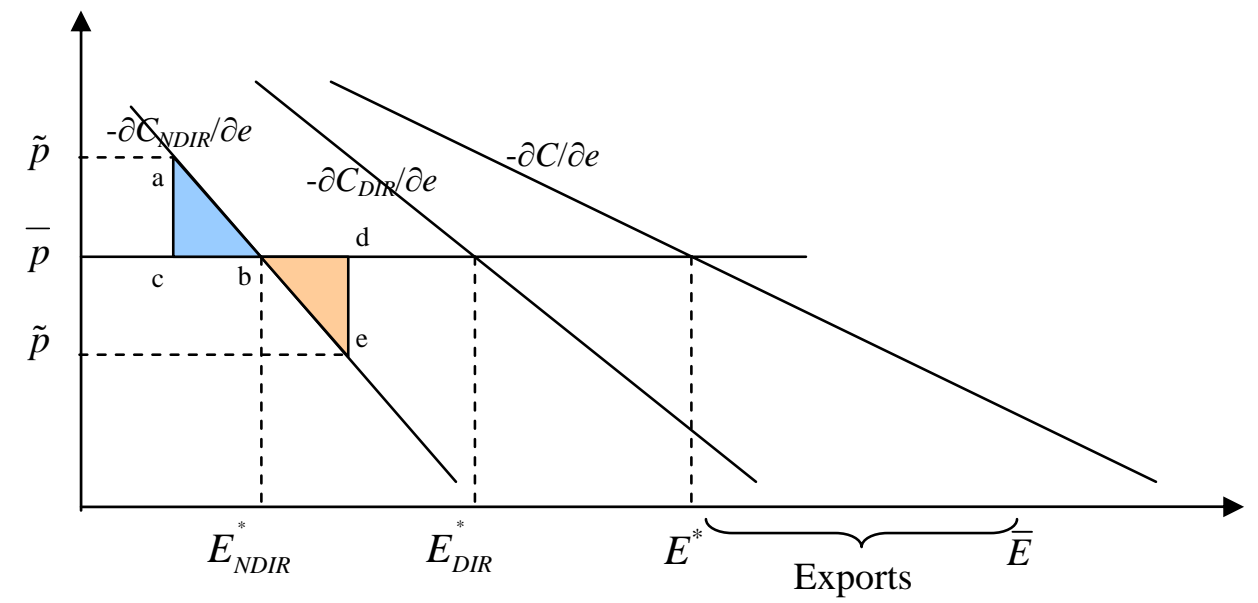

Figure 1: Optimal emissions in NDIR and DIR sectors at an international emissions price $\bar{p}$ 
The efficient solution could be decentralized by imposing uniform emission taxes at the international permit price $\bar{p}$ on the NDIR sectors that are not eligible for international emissions trading. The remaining emissions budget, $\bar{E}-E_{N D I R}^{*}$, would be allocated to the $D I R$ sectors that are eligible for international emissions trading. The optimal fraction of the emissions budget to be allocated to DIR sectors amounts to $\theta^{*}=\left(\bar{E}-E_{N D I R}^{*}\right) / \bar{E}=E_{D I R}^{*} / \bar{E}$. Depending on the business-as-usual emissions $E_{D I R}^{0}$ for DIR sectors, the optimal fulfillment factor $\lambda^{*}$ which reports the fraction of business-as-usual emissions that are freely allocated as allowances equals $E_{D I R}^{*} / E_{D I R}^{0}$. In policy practice, partitioning of $\bar{E}$ will generally deviate from efficient values $\lambda^{*}$ due to inherent information problems. ${ }^{4}$ These deviations will induce efficiency losses as indicated by the shaded areas $a b c$ (if the international emissions price $\tilde{p}$ presumed by the national authority is above the actual international price $\bar{p}$ ) or bde (if the international emissions price $\tilde{p}$ presumed by the national authority is below the actual international price $\bar{p}$ ).

\section{Numerical Model and Parameterization}

In order to provide empirical estimates for the magnitude of efficiency losses induced by hybrid carbon regulation, we transform our stylized analytical framework into a simple numerical model based on marginal abatement cost curves for Germany.

These curves represent the marginal costs of reducing carbon emissions by different amounts within a sector. Marginal costs of abatement may vary across sectors due to differences in carbon intensity, initial energy price levels, or the ease of carbon substitution possibilities.

For the empirical specification of sector-specific marginal abatement costs curves we adopt a flexible polynomial function of third degree:

${ }^{4}$ Obviously, lobbying of interest groups for generous allocations of allowances provides a further reason for deviations. 


$$
-C_{i}^{\prime}\left(e_{i}\right)=a_{1, i}\left(e_{o_{i}}-e_{i}\right)+a_{2, i}\left(e_{o_{i}}-e_{i}\right)^{2}+a_{3, i}\left(e_{o_{i}}-e_{i}\right)^{3} \quad i \in\{D I R, N D I R\}
$$

where $C_{i}^{\prime}$ are the marginal costs of reducing carbon emissions in sector $i, e_{o_{i}}$ are the businessas-usual emissions, and $e_{i}$ are the actual emissions, i.e., $\left(e_{o_{i}}-e_{i}\right)$ denotes the level of abatement. In order to determine the coefficients $a_{1, i}, a_{2, i}$, and $a_{3, i}$, we employ a least-square procedure based on a sufficiently large number of discrete observations for marginal abatement costs and the associated emission reduction in each sector. These values are generated with PACE - a standard multi-sector, multi-region computable general equilibrium model of international trade and energy use (see e.g. Böhringer 2000, 2001, 2002 for applications and algebraic documentation) based on GTAP5 data (see Dimaranan and McDougall 2002). ${ }^{5}$ Table 1 provides a summary of least-square estimates for the coefficients of marginal abatement cost curves for DIR and NDIR sectors in Germany.

Table 1: Coefficients for sector-specific marginal abatement cost functions in Germany

\begin{tabular}{r|r|r|r|r|r}
\hline \multicolumn{3}{c|}{} & \multicolumn{3}{|c}{ Non-Directive Sectors (NDIR) } \\
\hline$a_{1, \text { DIR }}$ & $a_{2, \text { DIR }}$ & $a_{3, \text { IIR }}$ & $a_{1, N D I R}$ & $a_{2, \text { NDIR }}$ & $a_{3, N D I R}$ \\
\hline 1.60372 & 0.00318 & 0.00042 & 5.76568 & 0.08324 & 0.00095 \\
\hline
\end{tabular}

The numerical model is implemented in GAMS (Brooke, Kendrick, and Meeraus 1987) using PATH (Dirkse and Ferris 1995) as a solver. The algebraic model formulation is given in Appendix A. The GAMS programming code is provided in Appendix B.

\section{Scenarios and Results}

Table 2 summarizes the evolution of emissions and emission reduction requirements for Germany vis-à-vis the EU average based on most recent business-as-usual projections by the EU (EU 2003b).

\footnotetext{
${ }^{5}$ We perform a series of model calculations with stepwise increases in sectoral emissions constraints for Germany which deliver pairs of emission abatement and associated marginal abatement costs used subsequently as input for the least-square approximation of continuous marginal abatement cost curves.
} 
Obviously, the effective reduction targets under the EU-BSA can change dramatically along the business-as-usual development. ${ }^{6}$ Germany committed itself under the EU-BSA to an emissions reduction target of $21 \%$ compare to 1990 emission levels. Against business-as-usual emission levels in 2005 , the effective reduction requirement only amounts to $8.7 \%{ }^{7}$

Table 2: $\mathrm{CO}_{2}$ emissions and reduction requirements (EU 2003b)

\begin{tabular}{l|c|r|r|r}
\hline & \multicolumn{2}{|c|}{$\mathrm{CO}_{2}$ emissions (in Mt) } & \multicolumn{2}{c}{ Reduction requirements (in \%) } \\
& 1990 & 2005 & 1990 & 2005 \\
\hline Germany & 943.0 & 815.6 & 21.0 & 8.7 \\
EU-15 (total) & 3071.5 & 3140.2 & 8.6 & 10.6 \\
\hline
\end{tabular}

In order to illustrate the excess costs for hybrid carbon regulation, we plot Germany's compliance costs as a function of the international $\mathrm{CO}_{2}$ price and the domestic fulfillment factor $\lambda$. The latter has been a central parameter of negotiations between the national regulatory authorities and the DIR sectors covered by the EU-ETS. Obviously, the DIR sectors had a strong incentive to lobby for large fulfillment factors in order to reduce effective reduction requirements vis-à-vis their business-as-usual emissions. A review of NAPs that have been approved so far by the EU Commission indicates rather generous allocation of emission allowances to the DIR sectors with $\lambda$ being close or even beyond 1 (Gilbert et al. 2004). As to Germany, the fulfillment factor is 1 , i.e., the DIR sectors are more or less endowed with their business-as-usual emissions.

Figure 2 provides a contour plot of total compliance costs for Germany across a meaningful range of international $\mathrm{CO}_{2}$ prices and fulfillment factors: (i) Reflecting broad consensus of carbon market analysts, international $\mathrm{CO}_{2}$ prices will not exceed $20 €$ per ton of $\mathrm{CO}_{2}$ in the initial phase of the EU-ETS, and (ii) fulfillment factors for Germany range between 0.8 and 1

\footnotetext{
${ }^{6}$ We apply the EU Burden Sharing Agreement covering all greenhouse gases to $\mathrm{CO}_{2}$ only which is by far the most important greenhouse gas within the EU.

${ }^{7}$ The major source for the decrease in emissions since 1990 can be traced back to so-called wall-fall profits in the context of Germany's reunification with a sharp decline in East-Germany's emissionintensive production together with more efficient energy transformation utilities.
} 
covering efficient fulfillment factors (as an endogenous function of the international $\mathrm{CO}_{2}$ price) as well as the negotiated fulfillment factor of 1 .

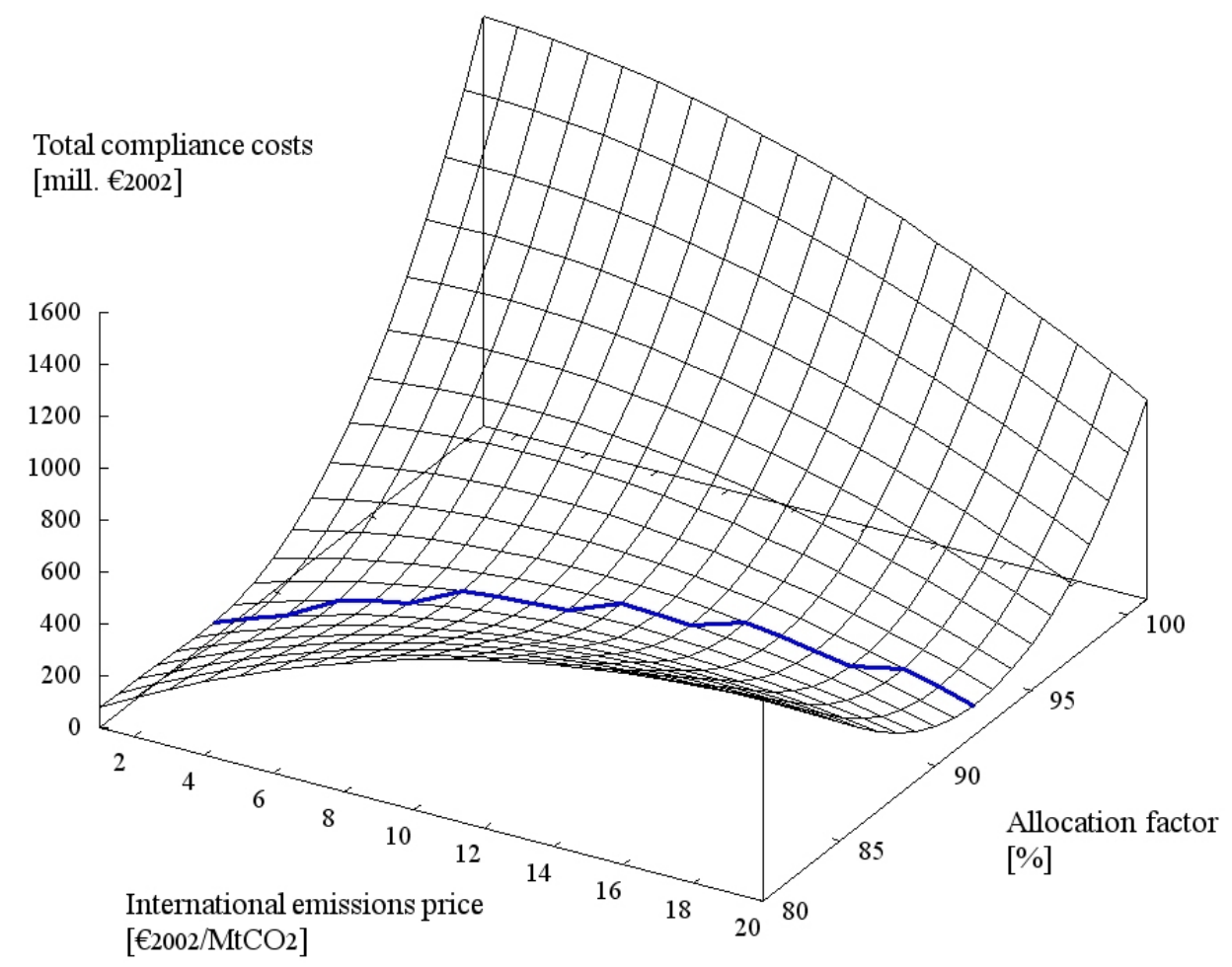

Figure 2: Total compliance costs for Germany (mill. $€_{2002}$ )

The marked solid line in Figure 2 reports the minimal compliance costs for Germany given alternative international $\mathrm{CO}_{2}$ prices $p$ and the associated efficient choice $\lambda^{*}$ of the fulfillment factor. At a given international $\mathrm{CO}_{2}$ price, compliance costs become the higher, the more the national authority deviates from the efficient fulfillment factor - this explains the U-shaped hull around the minimum cost line. Total excess costs of sub-optimal choices for $\lambda$ emerge as the difference between compliance costs for the respective $\lambda$ and the minimum costs for $\lambda^{*}$. Total compliance costs are composed of direct abatement costs for all sectors and the value of emission allowances that can be traded via the DIR sectors. Whenever $\lambda$ deviates from $\lambda^{*}$ the marginal abatement costs in NDIR sectors are no longer equalized with marginal abatement costs in DIR sectors - the latter always coinciding with the international emissions price $p$. If 
$\lambda$ is higher than $\lambda^{*}$, which is actually the case for Germany over the whole selected range of international emissions prices, the effective reduction burden for $N D I R$ sectors becomes more stringent leading to higher marginal abatement costs than $p$ and an increase in NDIR compliance costs. While the DIR sectors gain and may even achieve substantial net revenues from carbon exports, total compliance costs for DIR and NDIR sectors go up. ${ }^{8}$

Figures 3 and 4 decompose the total compliance costs into the components for NDIR and DIR sectors. In both figures, the minimum cost line for efficient NAPs is marked. Compliance costs for NDIR sectors are equal to the sum of direct abatement costs across these sectors, whereas compliance costs for DIR sectors in addition include the value of exported or imported $\mathrm{CO}_{2}$ allowances. The shape of NDIR compliance costs is straightforward: Independent of the international allowance price, abatement costs of NDIR sectors are determined by the effective reduction requirement associated with the choice of $\lambda$. We can see that NDIR compliance costs sharply increase in $\lambda$, thereby reflecting empirical evidence on costly abatement options in important segments of the domestic economy such as traffic and transportation that are not covered by the EU-ETS. In turn, compliance costs in DIR sectors at a given international price decrease in $\lambda$ rendering negative costs (or likewise net revenues) via permit exports if free allowance allocation is sufficiently high.

The value of allowance trade is illustrated in Figure 5. Whenever this value drops to zero, the associated fulfillment factor $\lambda$ characterizes an autarky situation for the given international emissions price $p$.

\footnotetext{
${ }^{8}$ The same logic applies, if $\lambda$ was lower than $\lambda^{*}$ : Here the marginal abatement costs for NDIR sectors drop below $p$, thereby reducing NDIR compliance costs at the expense of diminishing gains from emissions trading for the DIR sectors.
} 
Total compliance costs of $D I R$ sectors [mill. €2002]

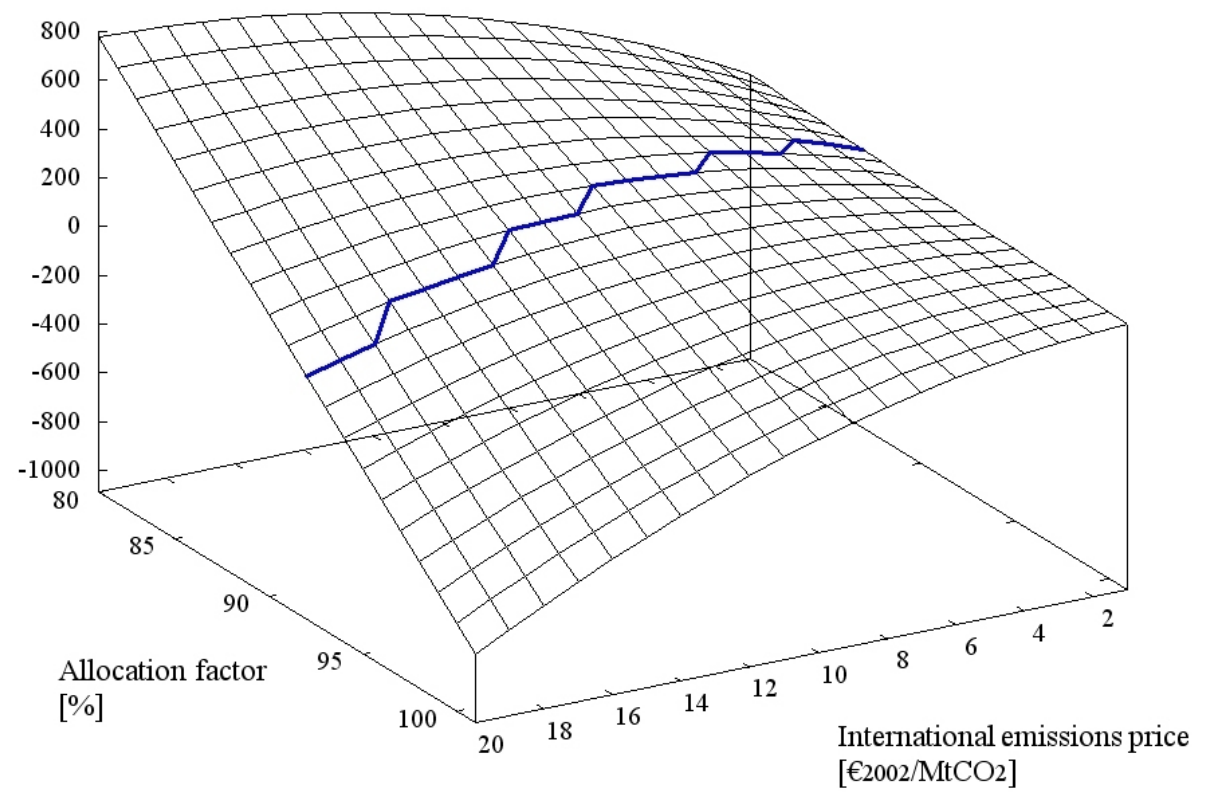

Figure 3: Compliance costs of DIR sectors in Germany (mill. $€_{2002}$ )

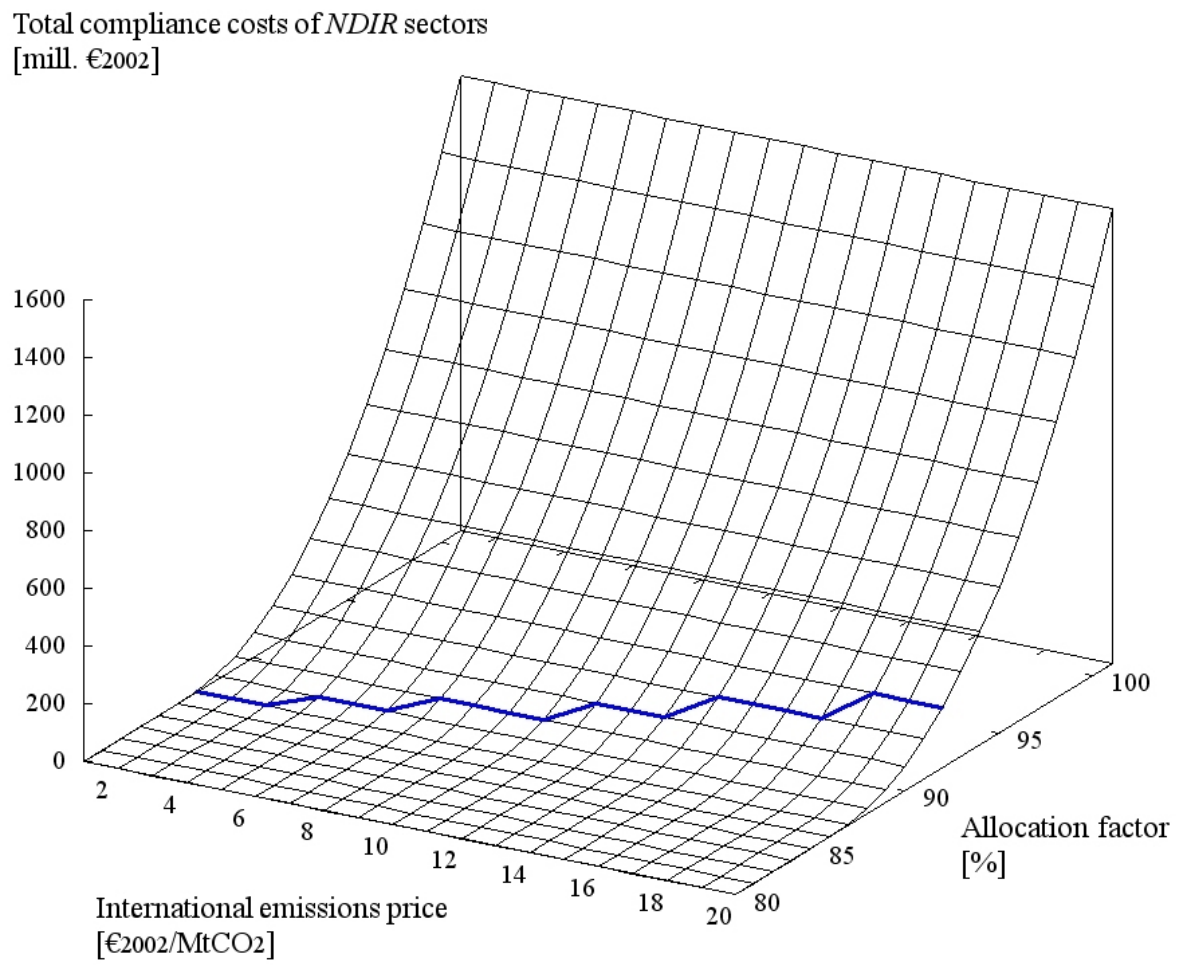

Figure 4: Compliance costs of NDIR sectors in Germany (mill. $€_{2002}$ ) 


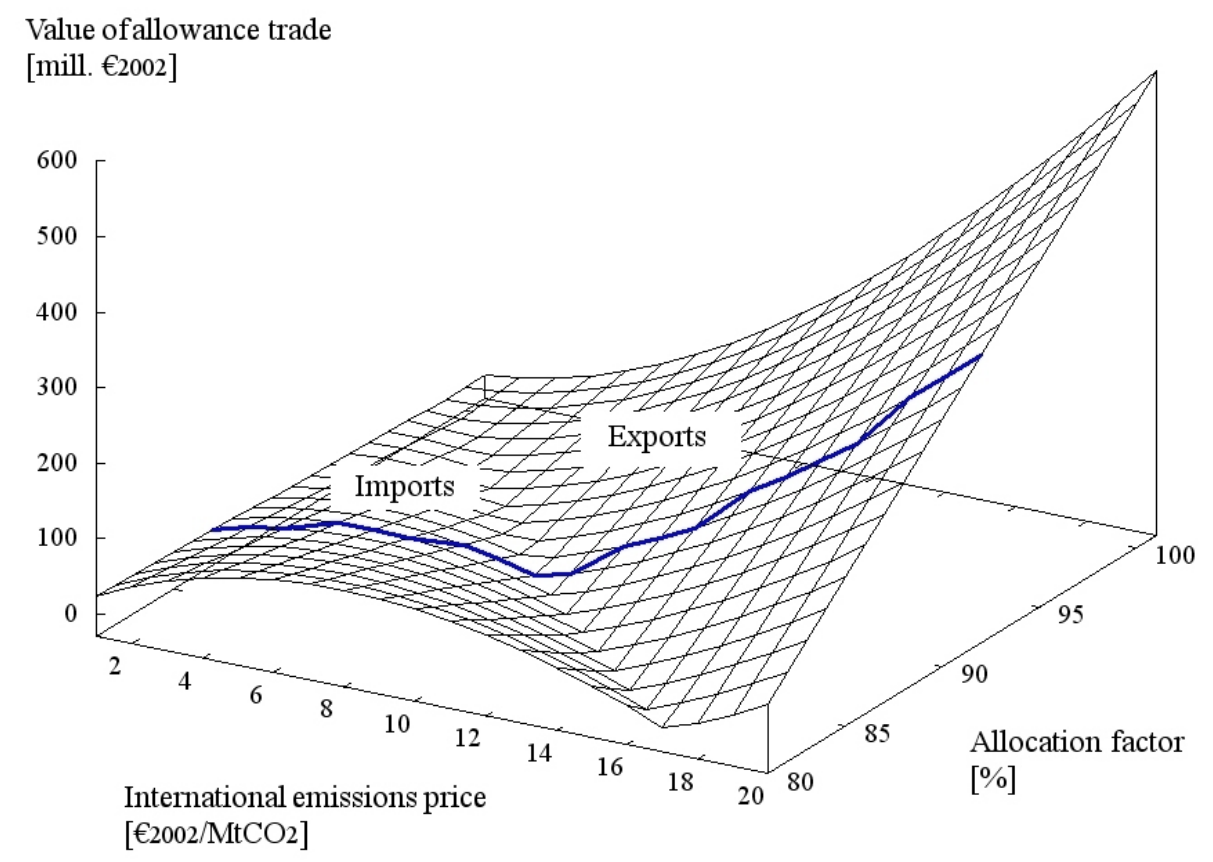

Figure 5: Value of allowance trade (mill. $€_{2002}$ )

The decomposition of compliance costs for DIR and NDIR sectors not only provides useful information on the sources of excess costs from hybrid regulation but also de-masks an important equity dimension: A generous allocation of free emission allowances to DIR sectors may fully shift the burden of emission reduction under the EU-BSA to the NDIR sectors (see Böhringer at al. 2005) whereas DIR sectors may be better off compared to business-as-usual. For concreteness, consider an international permit price of $10 €$ per ton of $\mathrm{CO}_{2}$ : With an efficient $\lambda^{*}$, total compliance costs for Germany amount to 305 mill. $€_{2002}$ as the sum of DIR costs (260.2 mill. $\left.€_{2002}\right)$ and NDIR costs (44.8 mill. $\left.€_{2002}\right)$. If the fulfillment factor is chosen at 1, total compliance costs more than quadruple to $1,362.8$ mill. $€_{2002}$. Apart from the large excess costs, the change in compliance costs between DIR and NDIR sectors vis-à-vis the efficient solution is dramatic: NDIR sectors have to bear a burden of $1,578,7$ mill. $€_{2002}$, whereas DIR sectors earn $215.9 €_{2002}$ through exports of free allowance. 
Our graphical exposition does not only visualize the excess costs and distributional impacts of inefficient choices for $\lambda$, it also illustrates the impending excess costs of hybrid regulation due to the lack of central planner information: Differences between various points on the minimum cost line provide information on the excess costs of hybrid carbon regulation when the national regulatory assumes the "wrong” international emissions price for pursued efficient partitioning of the national emissions budget. If, e.g., the national regulator expects an international $\mathrm{CO}_{2}$ price at $10 €$ per ton of $\mathrm{CO}_{2}$ and the "real" market price should materialize at $15 €$ per ton of $\mathrm{CO}_{2}$, the implied excess costs amounts to $23.6 €_{2002}$ which constitutes a cost premium of $8.9 \%$ above the central planner's minimum costs.

\section{Conclusions}

From 1 January 2005 onwards the European Union has launched the first large-scale international emissions trading program. The EU Emissions Trading Scheme (EU-ETS) in principle has the opportunity to advance the role of market-based policies in environmental regulation and to form the basis for future European and international climate policies.

In this paper, we have highlighted a central pitfall of the current EU-ETS that could seriously limit its efficiency thereby weakening arguments for a market-based regulation course. The EU-ETS under the European Burden Sharing Agreement implies a hybrid regulation scheme as sectors of domestic economies that are not covered by the emissions trading scheme require complementary emission regulation. Under a hybrid scheme, the domestic regulator must have perfect information on the international emissions price as well as the (marginal) abatement cost curves across all domestic emission sources in order to implement the single costminimizing abatement policy. Therefore, the current EU policy design for emission abatement discards a central element of market-based regulation, i.e. decentralized markets that autonomously achieve efficient use of scarce resources.

The pitfall of hybrid regulation becomes particularly policy-relevant when we account for distributional constraints. As a matter of fact, the EU-ETS has been only approved by EU 
Member States under the condition that emission allowances to sectors covered by the trading scheme are handed out for free. Whereas lump-sum grandfathering of allowances would not interfere with overall efficiency in a single comprehensive emission market, this is no longer the case with hybrid markets. Our numerical simulations based on empirical data for Germany have illustrated the impending large excess costs of hybrid regulation if allowance allocation to EU-ETS sectors deviates from the efficient level.

The deficiency of current EU emission regulation, however, should not be construed as an argument against emissions trading or market-based instruments per se. The problems arise from hybrid regulation that creates separate emission markets. As a consequence, the EU-ETS should be expanded in the future to include all domestic sectors of EU economies thereby creating a single emission market.

\section{References}

Böhringer, C. (2000), Cooling Down Hot Air - A Global CGE Analysis of Post-Kyoto Carbon Abatement Strategies, Energy Policy 28, 779-789.

Böhringer, C. (2001), Industry-level Emission Trading between Power Producers in the EU, Applied Economics 34 (4), 523-533.

Böhringer, C. (2002), Climate Politics From Kyoto to Bonn: From Little to Nothing?, The Energy Journal 23 (2), 51-71.

Böhringer, C. and A. Lange (2005a), On the Design of Optimal Grandfathering Schemes for Emission Allowances, European Economic Review (forthcoming).

Böhringer, C. and A. Lange (2005b), Mission Impossible !? On the Harmonization of National Allocation Plans under the EU Emissions Trading Directive, Journal of Regulatory Economics, 27 (1), 81-94.

Böhringer, C., T. Hoffmann, A. Lange, A. Löschel, and U. Moslener (2005): Assessing Emission Regulation in Europe, Energy Journal (forthcoming).

Brooke, A., D. Kendrick, and A. Meeraus (1987), GAMS: A User's Guide, Scientific Press, South San Francisco.

Dimaranan, B. and R.A. McDougall (2002), Global Trade, Assistance and Production: The GTAP 5 Data Base, West Lafayette: Center for Global Trade Analysis, Purdue University. 
Dirkse, S. and M. Ferris (1995), The PATH Solver: A Non-monotone Stabilization Scheme for Mixed Complementarity Problems, Optimization Methods and Software, 5, 123-156.

EU (1999), EU Council of Ministers, Commission Communication, Preparing for Implementation of the Kyoto Protocol, COM (1999), Annex 1, available at: http://europa.eu.int/comm/environment/docum/99230_en.pdf.

EU (2003a), Directive establishing a scheme for greenhouse gas emission allowance trading within the Community and amending Council directive 96/61/EC, European Commission, Brussels, available at:

http://europa.eu.int/comm/environment/climat/030723provisionaltext.pdf.

EU (2003b), European Energy and Transport Trends to 2030, European Commission, Brussels.

Gilbert, A., J.-W. Bode, and D. Phylipsen (2004), Analysis of the National Allocation Plans for the EU Emissions Trading Scheme, Ecofys Interim Report, Utrecht, The Netherlands, available at: http://www.ecofys.com/com/publications/documents/ Interim_Report_NAP_Evaluation_180804.pdf.

OECD (2001), Database on environmentally related taxes in OECD countries. Available at: http://www.oecd.org/env/policies/taxes/index.htm

Rutherford, T. F. (1995), Extensions of GAMS for Complementarity Problems Arising in Applied Economics, Journal of Economic Dynamics and Control, 19, 1299-1324.

UNFCCC (1997), 'Kyoto Protocol to the United Nations Framework Convention on Climate Change’, FCCC/CP/L.7/Add.1, Kyoto. 


\section{Appendix A: Algebraic Model Formulation}

Cast as a planning problem, our model corresponds to a nonlinear program that seeks a costminimizing abatement scheme subject to initial emission allocation and institutional restrictions for emissions trading at the sectoral level. The nonlinear optimization problem can be interpreted as a market equilibrium problem where prices and quantities are defined using duality theory. In this case, a system of (weak) inequalities and complementary slackness conditions replace the minimization operator yielding a so-called mixed complementarity problem (see e.g. Rutherford 1995).

Two classes of conditions characterize the (competitive) equilibrium for our model: zero profit conditions and market clearance conditions. The former class determines activity levels (quantities) and the latter determines prices. The economic equilibrium features complementarity between equilibrium variables and equilibrium conditions: ${ }^{9}$ activities will be operated as long as they break even, positive market prices imply market clearance - otherwise commodities are in excess supply and the respective prices fall to zero.

In the generic setting - laid out below - each model sector faces a specific emissions constraint vis-à-vis the business-as-usual situation. Without institutional restrictions on the scope of "where"-flexibility, each sector can trade emissions with other domestic sectors (domestic market) or the international market at an exogenous international emissions price. Arbitrage (zero-profit conditions) determines the efficient level of emission abatement and emission imports or exports at the sectoral level. In the simulations of hybrid regulation under the EUETS, sectors that are not eligible for international emissions trading are excluded from exports and imports to the international market (the respective decision variables are fixed to zero and the associated equilibrium conditions are dropped). This will in general drive apart the marginal abatement costs for sectors outside the EU-ETS and those sectors that can trade internationally.

\footnotetext{
${ }^{9}$ In our algebraic exposition, the variable associated with each equilibrium condition is added in brackets and denoted with an orthogonality symbol $(\perp)$.
} 
Table A.1 summarizes the notations for variables and parameters.

Table A.1: $\quad$ Variables and parameters

\begin{tabular}{|c|c|}
\hline \multicolumn{2}{|r|}{ Variables: Activity levels } \\
\hline$D_{i}$ & Emission abatement by sector $i$ \\
\hline$M D_{i}$ & Imports of emission allowances by sector $I$ from domestic market \\
\hline$X D_{i}$ & Exports of emission allowances by sector $I$ to domestic market \\
\hline$M_{i}$ & Imports of emission allowances by sector $i$ from international market \\
\hline$X_{i}$ & Exports of emission allowances by sector $i$ to international market \\
\hline \multicolumn{2}{|r|}{ Variables: Price levels } \\
\hline$P_{i}$ & Marginal abatement costs by sector $i$ \\
\hline$P D$ & Price of domestically tradable allowances \\
\hline \multicolumn{2}{|r|}{ Parameters } \\
\hline Target $_{i}$ & Effective carbon emission reduction requirement for sector $i$ \\
\hline$a_{1, i}, a_{2, i}, a_{3, i}$ & Coefficients of marginal abatement cost function for sector $i$ \\
\hline $\bar{P}$ & Exogenous international emissions price \\
\hline
\end{tabular}

\section{Zero Profit Conditions}

1. Abatement by sector $i\left(\perp D_{i}\right)$ :

$$
a_{1, i} \cdot D_{i}+a_{2, i} \cdot D_{i}^{2}+a_{3, i} \cdot D_{i}^{3} \geq P_{i}
$$

2. Imports of allowances by sector $i$ from domestic market $\left(\perp M D_{i}\right)$ :

$$
P D \geq P_{i}
$$

3. Exports of allowances by sector $i$ to domestic market $\left(\perp X D_{i}\right)$ :

$$
P_{i} \geq P D
$$


4. Imports of allowances by sector $i$ from international market $\left(\perp M_{i}\right)$ :

$$
\bar{P} \geq P_{i}
$$

5. Exports of allowances by sector $i$ to international market $\left(\perp X_{i}\right.$ ):

$$
P_{i} \geq \bar{P}
$$

\section{Market Clearance Conditions}

6. Market clearance for abatement by sector $i\left(\perp P_{i}\right)$ :

$$
D_{i}+M_{i}+M D_{i} \geq \text { Target }_{i r}+X_{i}+X D_{i}
$$

7. Market clearance for domestically tradable allowances $\left(\perp P D_{i}\right)$ :

$$
\sum_{i} X D_{i} \geq \sum_{i} M D_{i}
$$




\section{Appendix B: GAMS Programming Code}

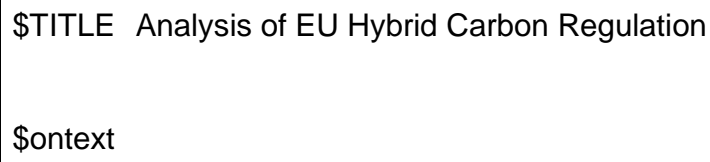

The Efficiency Costs of Separating Carbon Markets under the EU Emissions Trading Scheme:

A Quantitative Assessment for Germany

Christoph Böhringer, Tim Hoffmann, Casiano Manrique de Lara Peñate

correspondence: boehringer@zew.de

January, 2005

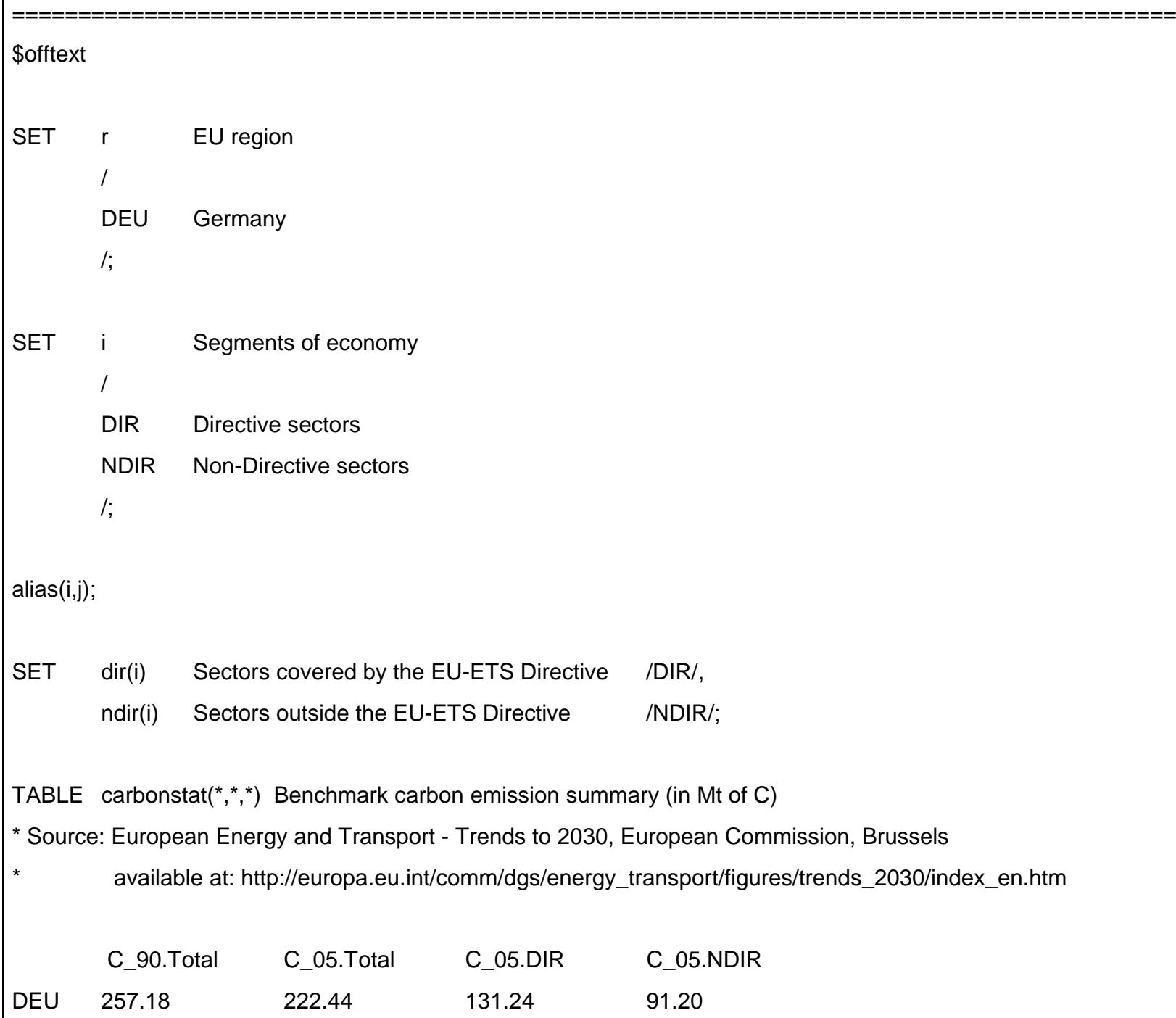

TABLE carbonstat $\left({ }^{*},{ }^{*},{ }^{*}\right)$ Benchmark carbon emission summary (in Mt of C)

* Source: European Energy and Transport - Trends to 2030, European Commission, Brussels

* available at: http://europa.eu.int/comm/dgs/energy_transport/figures/trends_2030/index_en.htm
C_90.Total
C_05.Total
C_05.DIR
C_05.NDIR

DEU 257.18 222.44 131.24 91.20 


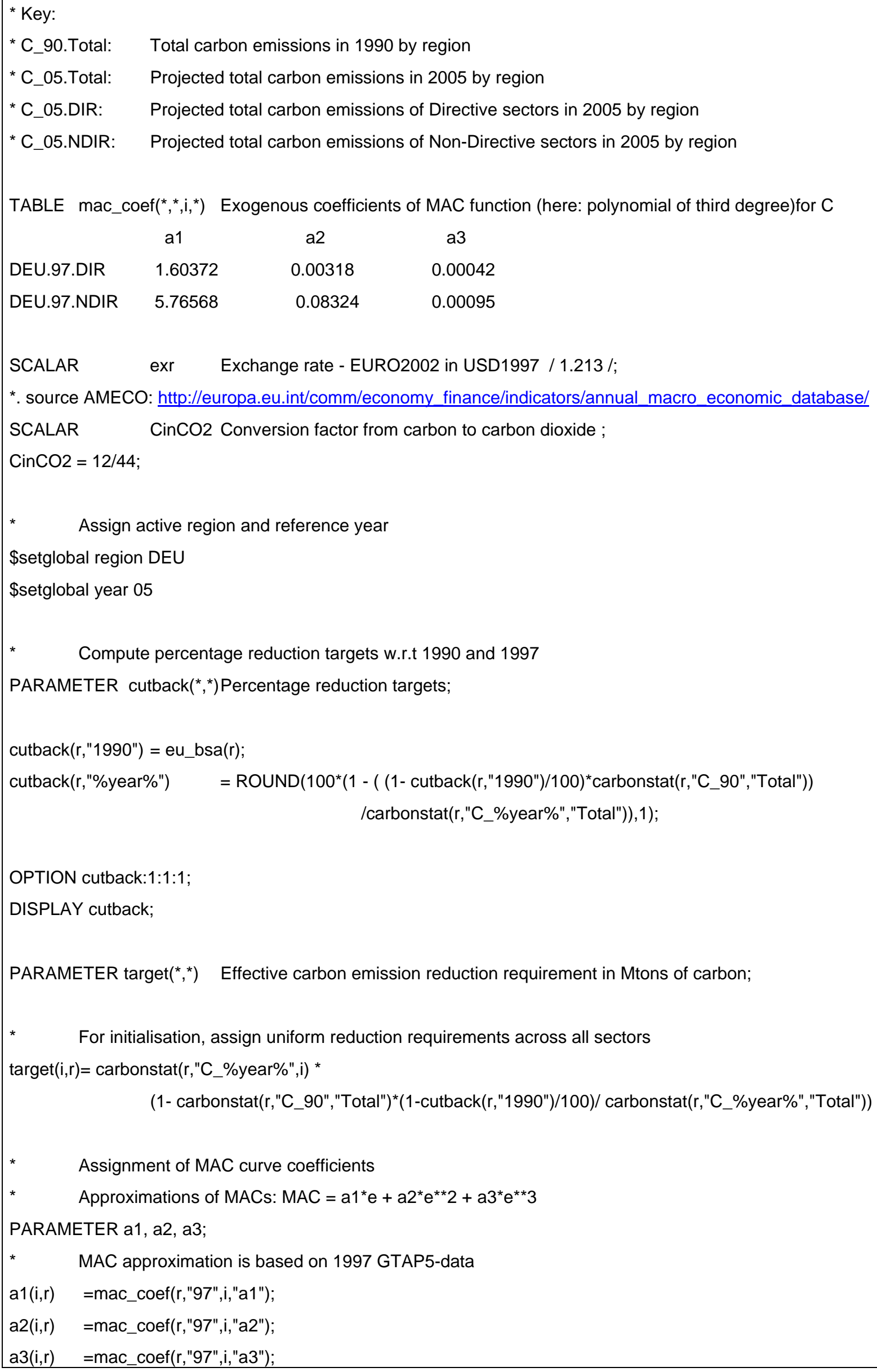




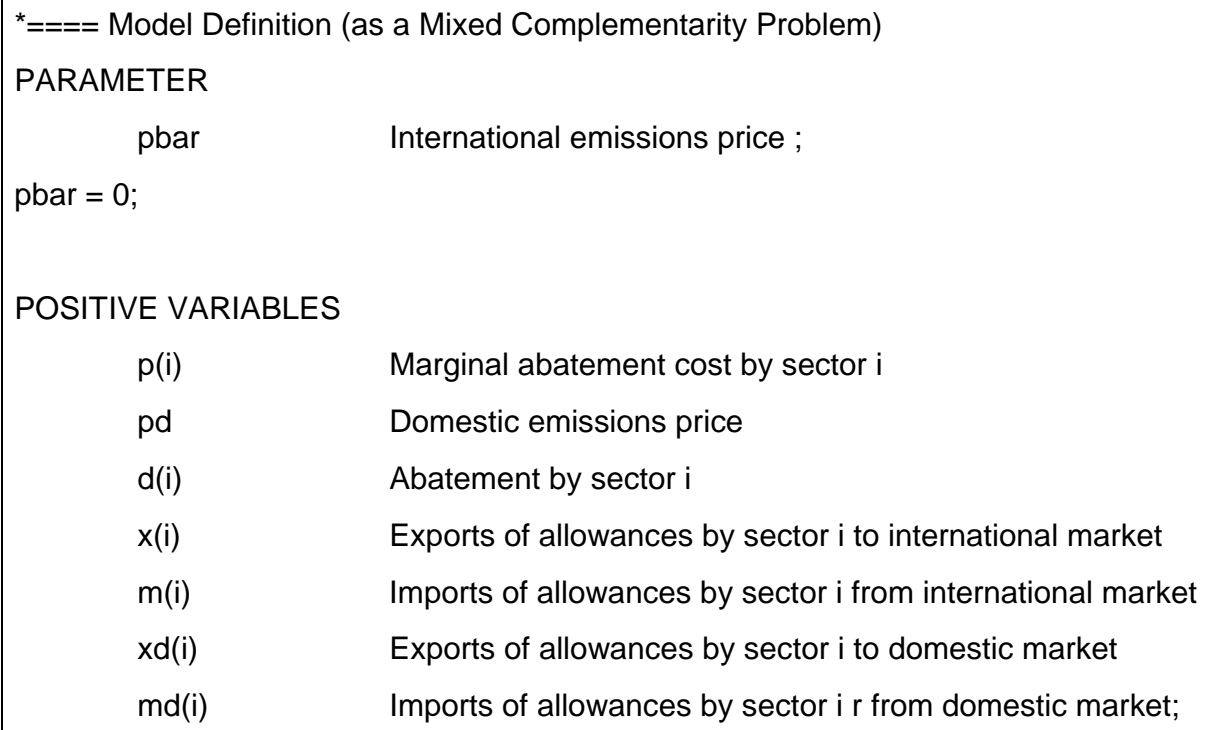

MODEL simac/mkt_p.p, mkt_pd.pd, zprf_d.d, zprf_m.m, zprf_x.x, zprf_md.md, zprf_xd.xd /; 